Session 2426

\title{
Low Cycle and Finite Life Fatigue Experiment
}

\author{
Bijan Sepahpour, Shou-Rei Chang \\ Department of Engineering \\ The College of New Jersey \\ Ewing, New Jersey 08628-0718
}

\begin{abstract}
An experiment for examination of fatigue failure theories is presented for potential adaptation at undergraduate mechanical and civil engineering programs. The focus of the experiment is placed on Low Cycle and Finite Life Fatigue. Design of the experiment and its associated apparatus allows for both symmetric (fully reversed) and non-symmetric reversed loading with different magnitudes applied to an array of cantilever beams. Several scenarios using beams with different lengths, sections, stress concentrations, and materials are proposed for destructive/fatigue failure testing. Other specimen with interesting features may be easily added to the package if desired. The time factor for conducting fatigue testing in an educational environment has been incorporated in the design process. Availability of the blueprints of all components of the robust apparatus, its cost effectiveness, ease of manufacture, and a proposed outline of the experiment make it an ideal addition to the archives of experiments in undergraduate engineering programs.
\end{abstract}

\section{I- INTRODUCTION}

Laboratory experimentation is a critical final link for a thorough understanding and appreciation of scientific and engineering theories. Every possible effort should be made not to deprive the future engineers or educators from this vital component of their education [1]. It is therefore necessary to continue development of effective and efficient pedagogical methods and techniques for the engineering laboratory experience [2].

Laboratory apparatus is generally expensive due to low production levels, specialized features and significantly higher Design Costs built into the final cost. For example, the range of cost for a typical educational fatigue testing apparatus is from $\$ 28,500$ to $\$ 32,500$. These units are basically adaptations of the R. R. Moore Industrial Fatigue testing devices which cost in excess of $\$ 100,000$.

Such high costs may lead to lack of vital laboratory apparatus and in turn deprive the engineering students from being sufficiently exposed to important concepts such as verification of the theory through experimentation, interpretation and analysis of data and gaining sufficient background for designing experiments. However, if blueprints of the designs of a (desired) apparatus are available, and on site machining capabilities exists, a major cut may be expected in the final cost. Such designs and blueprints may be generated in-house in collaboration with undergraduate engineering students [3]. The authors hope that the colleagues in other engineering programs would find this effort worthy of potential adaptation in their program. 


\section{II- OBJECTIVES OF THE PROJECT}

The following major objectives were set at the inception of the project;

1. To develop an experiment for examination of fatigue failure theories,

2. To create an opportunity for collaborative research and design efforts between engineering student(s) and faculty,

3. To generate a modular, cost-effective, reproducible apparatus with outstanding design characteristics,

4. To make all information necessary for fabrication of the apparatus and conducting the experiment available to engineering programs nationwide.

The authors invited three Junior engineering students (Andrew Maulbeck, Mary Anne Bitetto and Greg Conway) to collaborate with them in materializing the above goals. The parameters in successful implementation of the processes involved for achieving the above goals were comprehensively discussed, outlined and a preliminary Gantt chart was generated. Through ten weekly scheduled meetings, alternative designs for each of the components, subsystems and the overall integrated system were evaluated, chosen and optimized. It took another two weeks to fabricate, modify, and test the reliability and capabilities of the apparatus.

\section{III- Background}

Roark and Young define Fatigue as "the fracture of a material under many repetitions of a stress at a level considerably less than the ultimate strength of the material" [4 ]. In a fatigue test, the specimen may be exposed to equal or unequal alternating stresses. When equal positive and negative stresses are applied, it is said that the loading is fully reversed. In this situation, a critical location of the specimen will experience equal levels of both tensile and compressive stresses in one full cycle.

The benchmark for establishing the behavior of engineering materials under dynamic/fatigue loading is the "S-N" diagram. Here, "S" corresponds to the stress level and "N" to the number of cycles. Due to the uncertainties involved in material behavior and characteristics, a large number of specimens are tested at different stress levels for generating the " $S-\log N$ " diagram. Ideally, the main objective in such tests is two-fold. First, to establish (for a given material), up to what stress levels the material will enjoy an infinite life (Endurance Limit); and second, to correlate the number of cycles at different stress levels that a material will be able to go through before coming to failure.

The S-N diagrams for several engineering materials have been established as a result of comprehensive and highly time consuming tests. Generally, the results are more reliable for steel alloys compared to aluminum alloys. Low-cycle fatigue is defined on an S-N diagram as being approximately between zero and 1000 cycles. High-cycle fatigue is generally greater than $10^{3}$ cycles. Finite life is assumed to be below $10^{7}$ cycles [5]. A typical S-N diagram is shown in figure 1. 


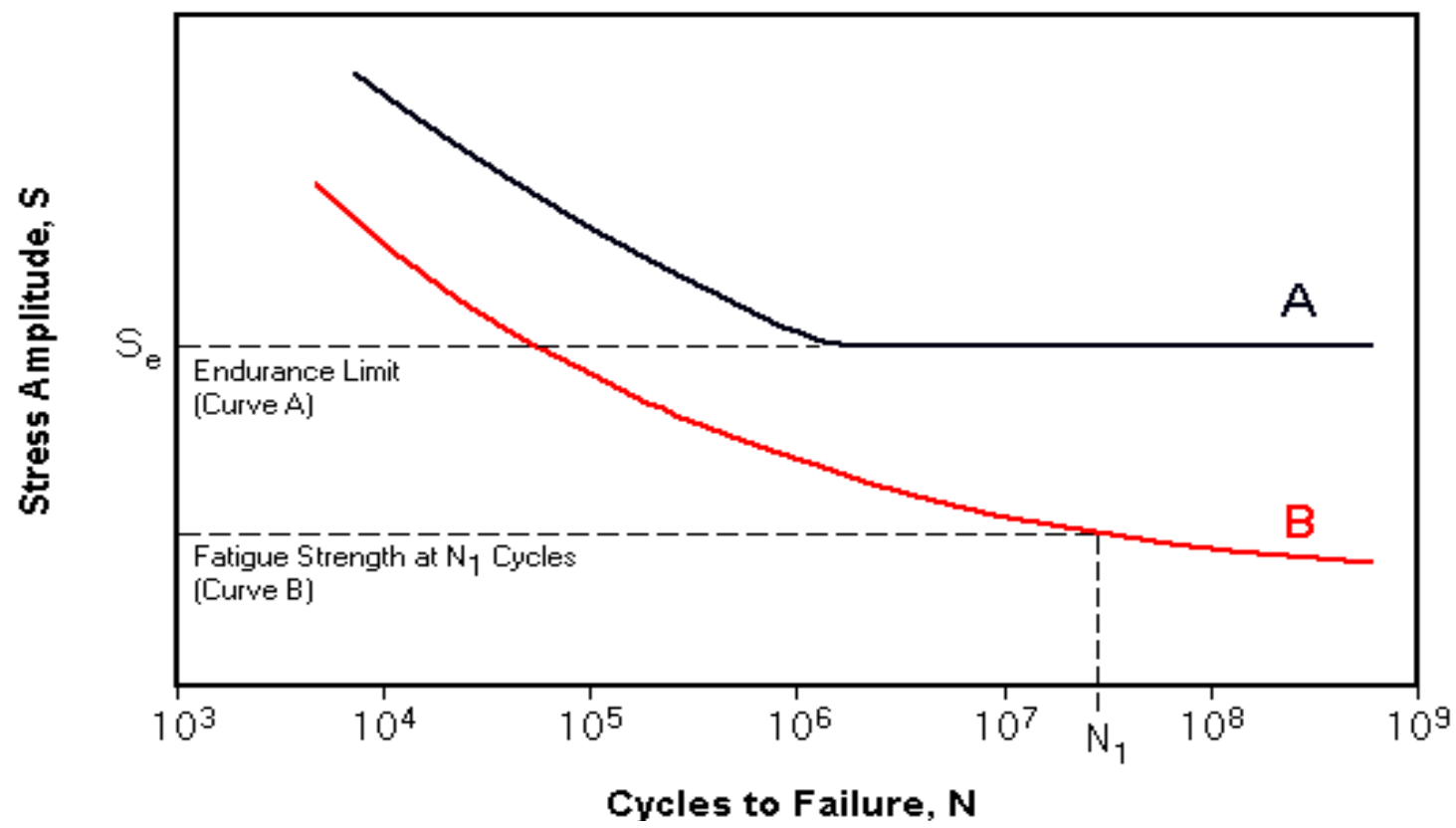

Figure 1 A Typical S-N Diagram.

Curve A - Typical behavior of steel alloys in fatigue loading, Curve B - Typical behavior of Aluminum alloys in fatigue loading.

Ferrous materials usually show a definite breaking point on the S-N diagram around $10^{6}$ cycles, whereas nonferrous metals show no such point. For nonferrous metals, a value of $5 \times 10^{8}$ cycles is usually assigned as the fatigue limit. There are several theories available for prediction of failure due to cyclic loading [6]. Depending on the situation at hand, the designer must apply the suitable theory as no one theory will optimally address all design requirement. However, all of them reflect on the fact that this type of failure is not yet completely understood and extra care must be taken when dealing with fatigue phenomenon. Shigley and Mischke present a rather comprehensive view of the issues involved with the variations of behavior of different materials in the fatigue analysis process [7]. The goal in the current experiment is to create and simulate the conditions that allow students to test the reliability of such $(S-N)$ diagrams and gain a better understanding of the (statistical and probabilistic nature of) Fatigue Failure Theories.

\section{IV-DESIGN OF THE EXPERIMENT AND ITS ASSOCIATED APPARATUS}

The following criteria have been incorporated in the design of the experiment and the associated apparatus:

- Safety

- Simplicity and Practicality in Fabrication (at other institutions)

- Affordability/Control of Cost

- Use of Reliable Sources for Components

- Durability

- Use of Non-Corrosive \& Aesthetically Pleasing Materials

- Simplicity of Operation

- NO use of Discontinued Parts/Components

- Time Factor in Conducting the Experiment 
The requirement of having a modular design and stopping the motor (when the specimen fails) presented some interesting challenges. Additionally, the size, weight, and other physical characteristics of the experiment were not defined at the inception of the project. This lack of constraints was a mixed blessing (for the students) since it did free the design process to vary these factors, but also removed these characteristics from being used as starting points in the process. Table (1) summarizes the parameters involved in the implementation of the project.

\begin{tabular}{|c||l||}
\hline \multicolumn{1}{|c||}{ \# } & \multicolumn{1}{c|}{ TYPE $\boldsymbol{O F}$ ACTIVITY } \\
\hline \hline 1 & Brainstorming for Design of the Experiment and the Apparatus \\
\hline 2 & Meeting Minutes and Progress Reports \\
\hline 3 & Prototyping \\
\hline 4 & Generation of Technical Drawings for all (Home Made) Components \\
\hline 5 & Selection of (commercial) Components and Identification of Suitable Sources \\
\hline 6 & Fabrication and Compilation of Notes on Best Approach for Machining \\
\hline 7 & Electro-mechanical control system \\
\hline 8 & Testing, Calibration, Generation of Data and Measure of Accuracy \\
\hline 9 & Generation of the Laboratory Manual for the Experiment \\
\hline 10 & Loading of All Necessary Information and Helpful Links on a CD (**) \\
\hline
\end{tabular}

Table 1 Parameters involved in the successful implementation of the project.

(**) This Information may be obtained from the first author.

\section{V- MATHEMATICAL MODELING}

To better appreciate the complexity of the fatigue phenomenon, mathematical models were generated, examined and used as a visual platform to decide on the degree of modularity of the apparatus. Further, they serve as indicators by which a laboratory coordinator/instructor may make more informed decisions about the time required for conducting the experiment/ demonstration. These models are presented in Appendix (A) [8].

\section{VI- DESIGN OF THE COMPONENTS AND SUBSYSTEMS OF THE APPARATUS}

The proposed Modular Fatigue Testing System is comprised of the following major components and subsystems.

1. Frame and the Cantilever Beam Support System/Stand(s),

2. Force Delivery linkage,

3. Counter and Motor Control system.

The role and design characteristics of each of these components are briefly discussed.

\section{The Frame and Beam Support Stand}

The Frame is constructed of MiniTec components due to their durability, cost effectiveness, and aesthetic appeal. MiniTec frames are capable of being rearranged to fit additional demands. 
This modular nature allows for upgrading the system in the future by only purchasing a few additional components instead of purchasing a completely new frame. The frame allows for supporting and running two testing devices simultaneously. It is equipped with four locking casters (that also resist rotation). The modularity of its design allows for conducting many other experiments at different periods of a typical laboratory course and easy storage when not in use.

The Beam Support System/Stand is required to support the specimen in a cantilever mode. These are made of aluminum and may be used for other experiments. Figure 2 shows the frame, and the two stands used to run tests on two different specimens at the same time. In the shown instant, the upper fibers of the specimens on the left and right are experiencing tensile and compressive stresses respectively.

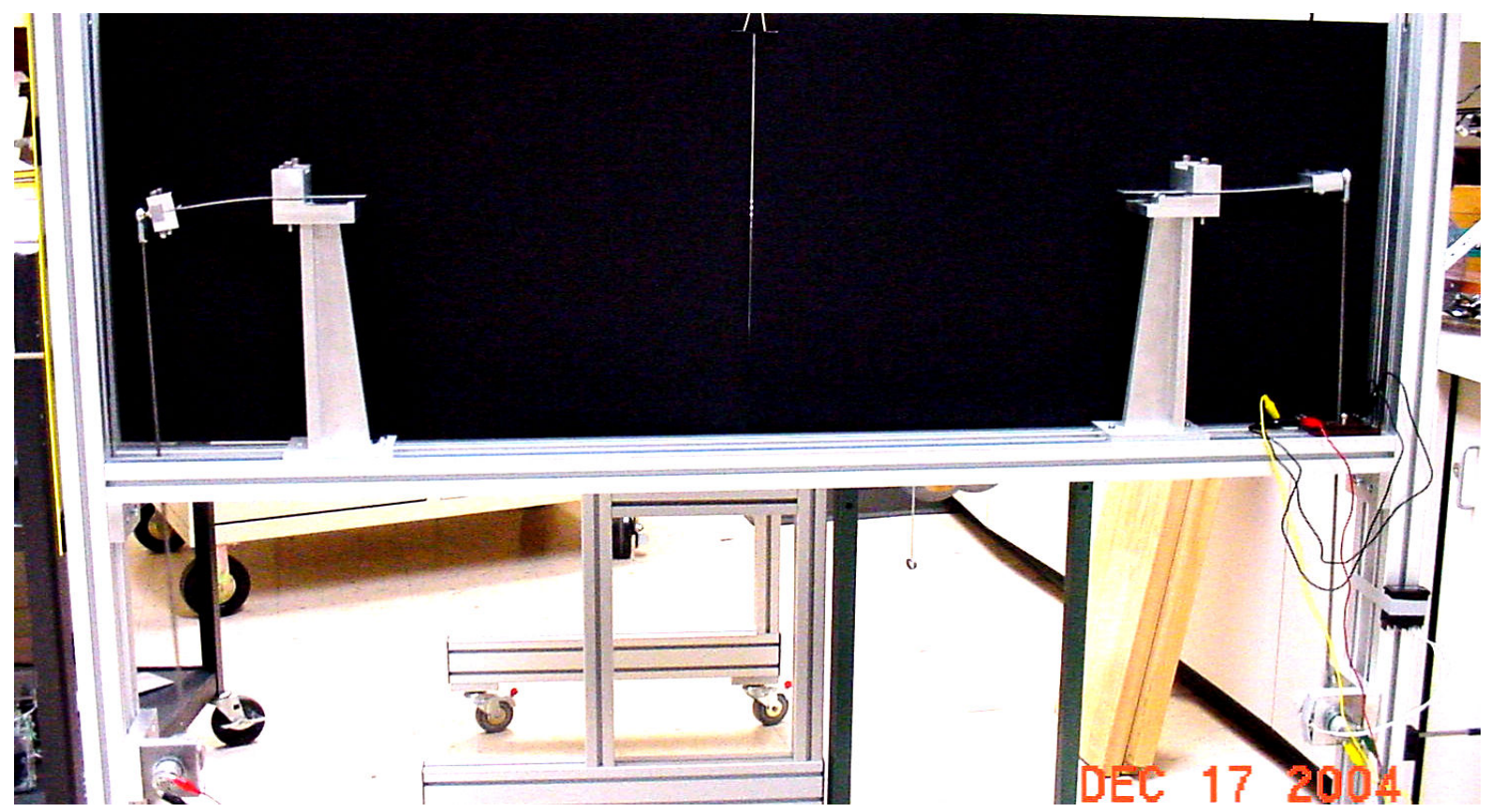

Figure 2 The Frame and the two Beam Support Stands used for running two different tests simultaneously.

\section{Force Delivery linkage}

Application of the force to the free end of the cantilever specimen is achieved through the use of a (simulated) 4-Bar Linkage. The Input link is a disc attached to a DC motor; the Coupler (the connecting rod) is a steel bar coupled to Heim joints at both ends; and the Output link is the specimen itself. This arrangement has proven to work satisfactorily. The input disc allows for several input lengths and the motor bracket may be adjusted for obtaining different combinations of desired alternating stresses. Figure 3 shows how the Force Delivery System has managed to create a fully reversed loading condition on an aluminum specimen. 

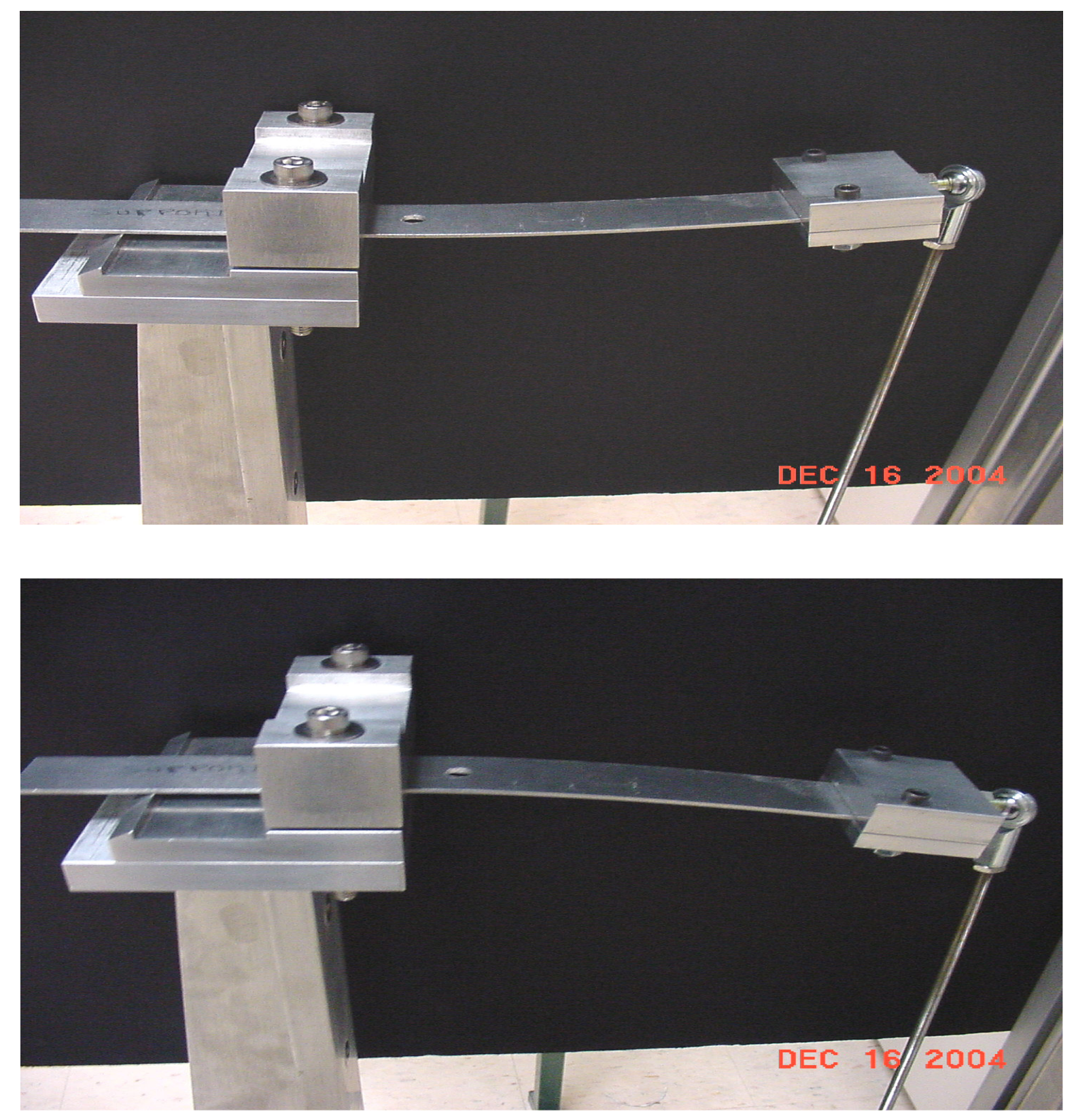

Figure 3 Display of the force delivery in a fully reversed loading on an aluminum specimen with a circular discontinuity near the fixed end.

\section{Counter and Motor Control system}

A seven digit counter with magnetic sensors is used to measure the number of cycles to failure. Next, the problem of stopping the motor (as the part fails) had to be addressed. Using the geometry of the system, a method for capturing the event of specimen failure was devised. It was recognized that if the specimen failed, the connecting rod would have a tendency to fall either towards or away from the beam support. It was determined that regardless of how the specimen failed; the position of the rod would quickly travel outside of its normal pattern. 
Because of this, a solution was chosen that places a limiting dimension on the horizontal travel of the connecting rod. Essentially, a pivoting fork was positioned around the connecting rod such that in normal operation, the connecting rod comes within 0.25 " of the legs of the fork. When the specimen fails, however, the connecting rod falls into a leg, causing the fork to pivot. This pivoting motion is used to actuate micro-switches that are interfaced with a relay. Upon actuation of these switches, the relay cuts the power to the motor. This solution is tested, and reliably stops the motor (and in turn the counter) when the specimen fails. Figure 4 shows the left and right legs of the fork leaning against the micro-switches.

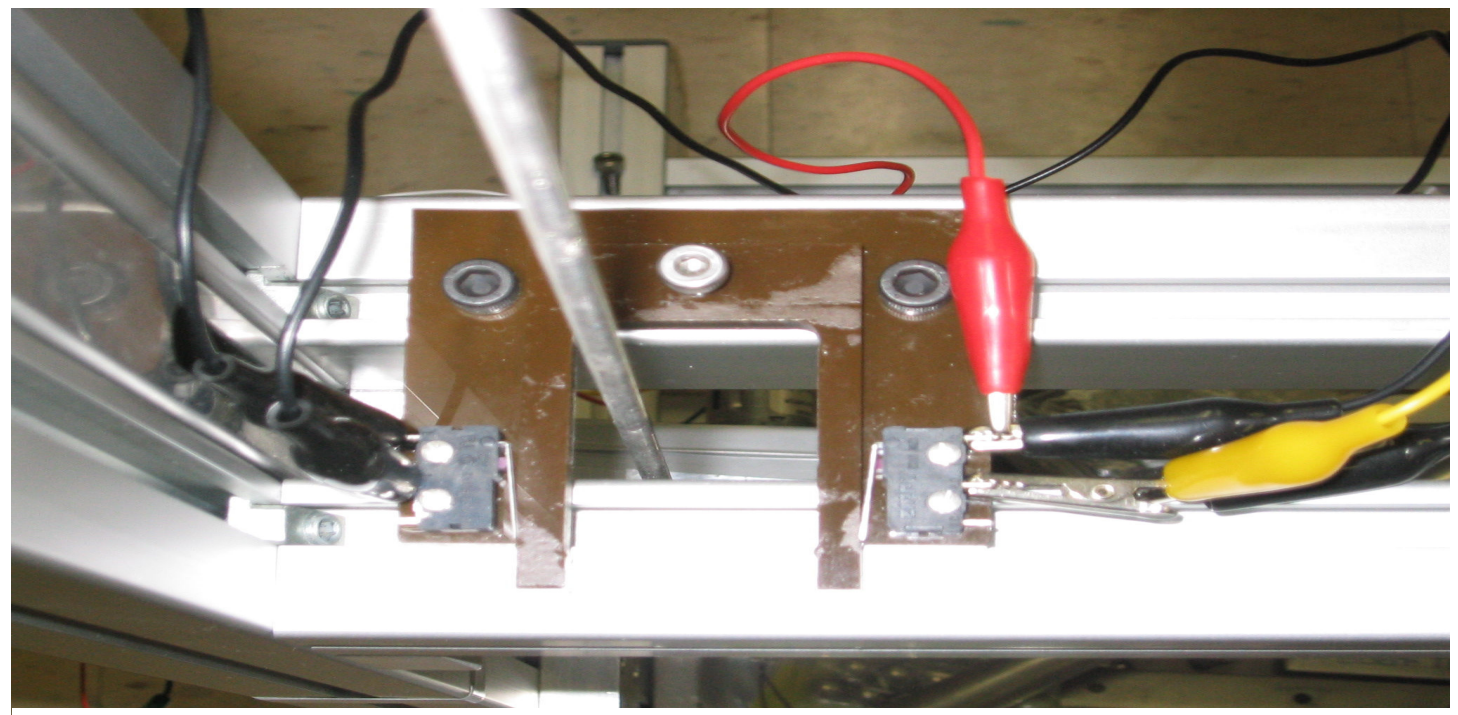

Fig. 4 Stopping Mechanism. Upon failure of the Specimen, the Connecting Rod will cause the Pivoting of the Fork which in turn activates the relay to shut the motor.

Figure 5 shows the 7-digit digital counter which is activated by a magnetic sensor package coupled with the rotating disc (input link) and the motor bracket.

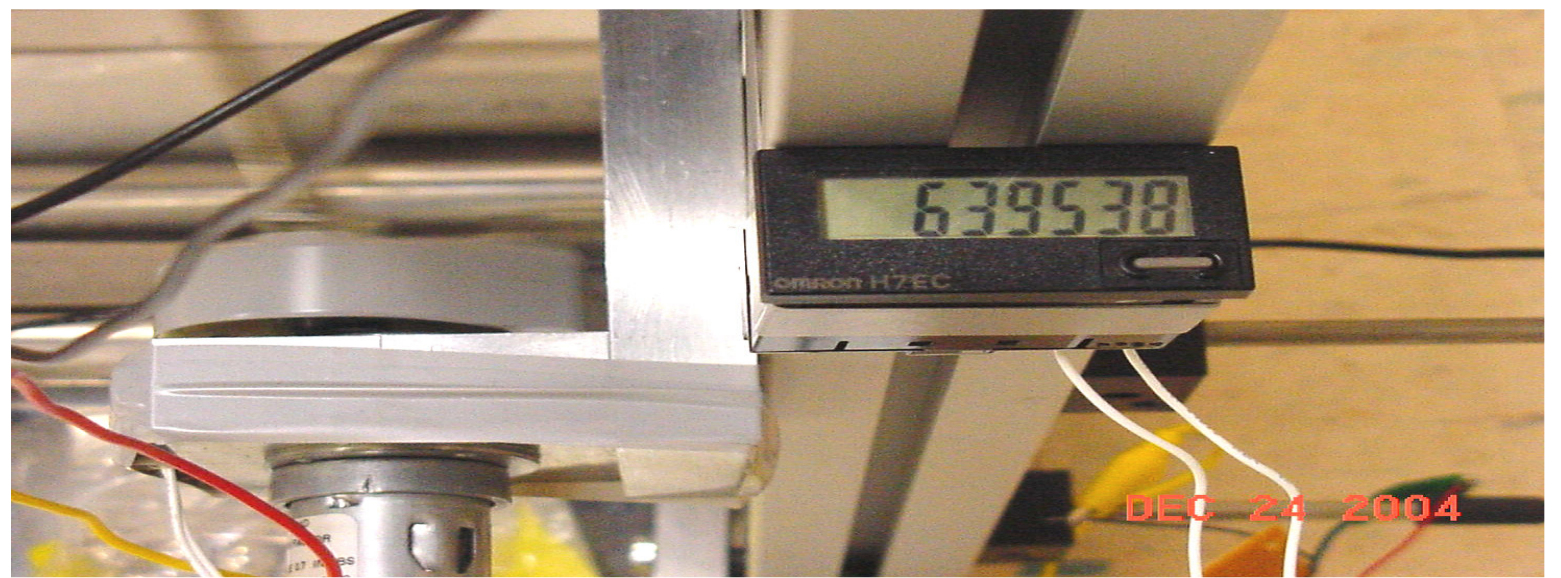

Figure 5 The Counter and the Sensors. The cylindrical magnet housed on the input link (the rotating disc) triggers the sensor (attached to the motor bracket) carrying signals to the digital counter. 


\section{VII- EXPERIMENTAL PROGRAM AND COLLECTION OF DATA}

The collection of data initiated since second week of December (2004). A significant number of specimens have been tested so far in the test program. This process has revealed some promising data. Several materials have been selected so far in the test program. Table (2) reflects on the properties of these materials. Figure 6 shows a sample of three aluminum alloy specimens with different geometries. Figure 7 shows two samples with Dog-Bone geometries (of which one has a discontinuity). The table in Appendix (B) is an abridged listing of the test results so far.

Although the testing program has resulted in some promising data, in general, the tested specimens consistently fail at higher number of cycles than those predicted by text book models. The authors speculate that this may be due to the combinational effects of the statistical/ conservative nature of the text book models and the conservative listings of the strength of materials in tables. We obtained a 1/8" x 1" x $6 \mathrm{ft}$. bar of Aluminum 6061-T6 with certification. The (average) Ultimate and Yield strength values listed on the certificate $\left(S_{U}=\right.$ $\left.47.34 \mathrm{kpsi}, S_{Y}=44.16 \mathrm{kpsi}\right)$ of this bar are considerably higher than those listed in conventional/text book tables $\left(S_{U}=45 \mathrm{kpsi}, S_{Y}=38-40 \mathrm{kpsi}\right)$. This is a critical issue in that when running the experiment, the factors of safety against the Ultimate and Yield strengths are set in the range of $1.1,1.15,1.2,1.25$, etc. Consider the following scenario.

If the actual Yield strength is $45 \mathrm{kpsi}$ and a listed table/book value of $40 \mathrm{kpsi}$ is used say with a factor of safety of 1.15; in reality a factor of safety of about 1.3 is in effect. The (HIDDEN) actual difference in this case may offset the result by tens of thousands of additional (unexpected) cycles. The tested specimens (machined) from the certified bar have shown significantly better results compared to the non-certified samples.

Because of the unforeseen circumstances (explained above), the testing program will continue until the best possible choices of materials and geometries are established for a better controlled environment. The interested parties may freely contact the first author for most updated and recommended procedures and choices of materials.

\section{VIII- OBSERVATIONS and RECOMMENDATIONS}

The following is a listing of the interesting observations made up to this point in the process:

1. All solid specimens failed at the edge support,

2. All specimens with discontinuities (near the fixed end) failed at the discontinuity,

3. All specimens with Dog-Bone geometry failed at the smaller sections near the fixed end,

4. Certified specimens fail at values closer to the predicted ones than the non-certified ones,

5. Steel specimens fail at values closer to the predicted ones than the Aluminum samples,

6. Failure of all specimens was abrupt-no warning,

7. The test results may be considered as Accurate but certainly not Precise.

The major obstacle to overcome is to reduce the number of cycles required for failure. This may be achieved by further examination of the text book models/equations and ascertaining materials that do not suffer from a large standard deviation from the expected mean. 
The following recommendations may be made at this stage of the task:

1. Avoid the use of thin sections as the variation in results is quite troublesome-(do not use sections with a thickness less than 1/8" for Steel and no less than 1/4" for Aluminum),

2. Work with specimens that have a Length to Width Ratio of $12 \leq \mathrm{L} / \mathrm{W} \leq 15$,

3. To avoid Edge Effect, use Dog-Bone geometry if possible,

4. Select motors that provide a reasonable combination of power and RPM,

5. If you choose to work with aluminum, don't set it as the base metal for the experiment,

6. Try to obtain material with certification as this may save you a great deal of time,

7. If possible, run a complete tensile test on a sample of the bars used for the specimens,

8. Exercise the safety precautions in this experiment to the full extent,

9. Obtain the most updated results and recommended procedures from the authors,

10. Share your findings and Alternative Solutions with the authors so that they may share them with other interested parties.

\begin{tabular}{|c|c|c|c|c|c|}
\hline Material & $\begin{array}{c}\text { Ultimate } \\
\text { Strength, } \\
{\left[\mathrm{S}_{\mathrm{U}}\right]} \\
\text { (psi) }\end{array}$ & $\begin{array}{c}\text { Yield } \\
\text { Strength, } \\
{\left[\mathbf{S}_{\mathbf{Y}}\right]} \\
\text { (psi) }\end{array}$ & $\begin{array}{c}\text { Fatigue } \\
\text { Endurance Limit, } \\
{\left[\mathrm{S}_{\mathrm{e}}\right]} \\
(\mathrm{psi})\end{array}$ & $\begin{array}{c}\text { Brinell } \\
\text { Hardness, } \\
{\left[\mathrm{H}_{\mathbf{B}}\right]} \\
500 \mathrm{Kg} \text { Load; } \\
\mathbf{1 0} \mathbf{~ m m} \text { Ball } \\
\end{array}$ & $\begin{array}{c}\text { Modulus of } \\
\text { Elasticity, } \\
{[\text { E ] }} \\
\text { (psi) }\end{array}$ \\
\hline $\begin{array}{l}\text { Aluminum } \\
6061-T 65 \\
\text { Certification } \\
\text { Available }\end{array}$ & 45,000 & 40,000 & 14,000 & 95 & $10,000,000$ \\
\hline (Alclad) & $(42,000)$ & $(37,000)$ & (Not Available) & (Not Available) & \\
\hline $\begin{array}{l}\text { Aluminum } \\
5052-H 32 \\
\text { (AVOID) }\end{array}$ & 33,000 & 28,000 & 17,0000 & 60 & $10,000,000$ \\
\hline (Alclad) & $(25,000)$ & $(21,000)$ & (Not Available) & (Not Available) & \\
\hline $\begin{array}{c}\text { Aluminum } \\
6063-T 5\end{array}$ & 27,000 & 21,000 & 10,000 & 60 & $10,000,000$ \\
\hline $\begin{array}{c}\text { Steel } \\
\text { 1018-HR } \\
\text { (Hot Rolled) } \\
\text { Recommended }\end{array}$ & 58,000 & 32,000 & (Not Available) & 116 & $29,000,000$ \\
\hline
\end{tabular}

Table 2 Text book/Table Listing of the Properties of the Materials Tested with the Apparatus. 


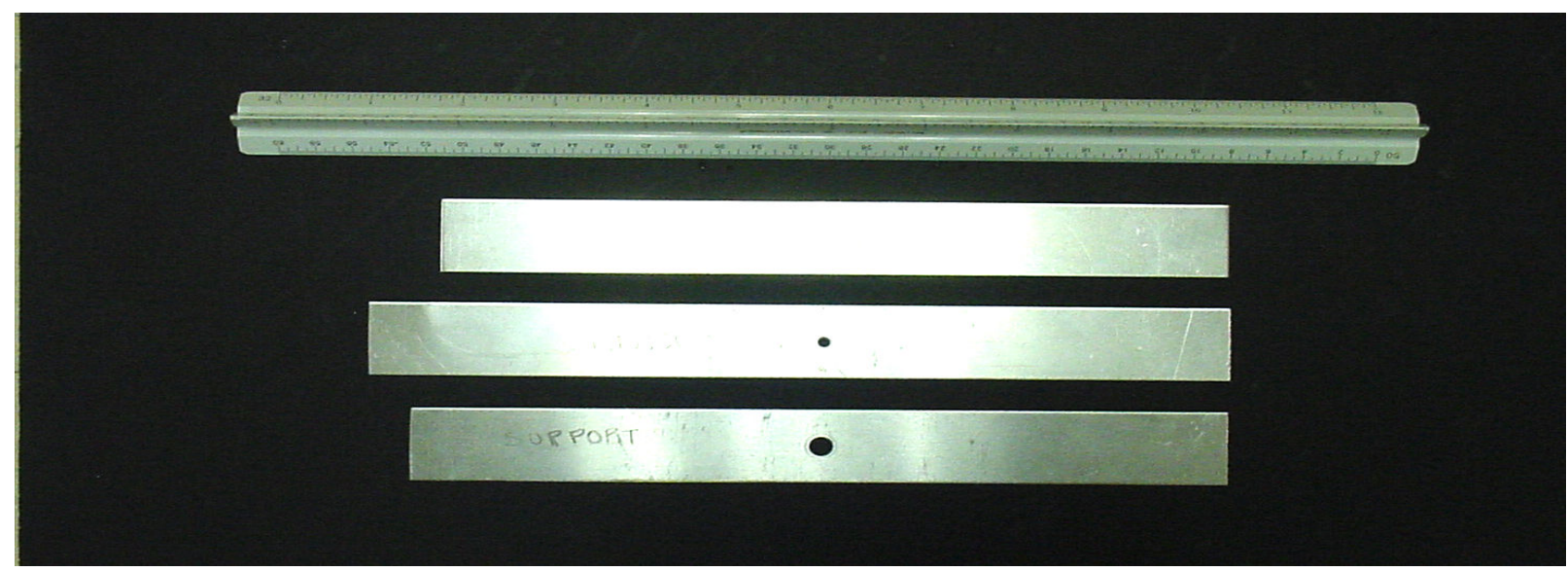

Figure 6 Samples of Specimens with Different Geometries.

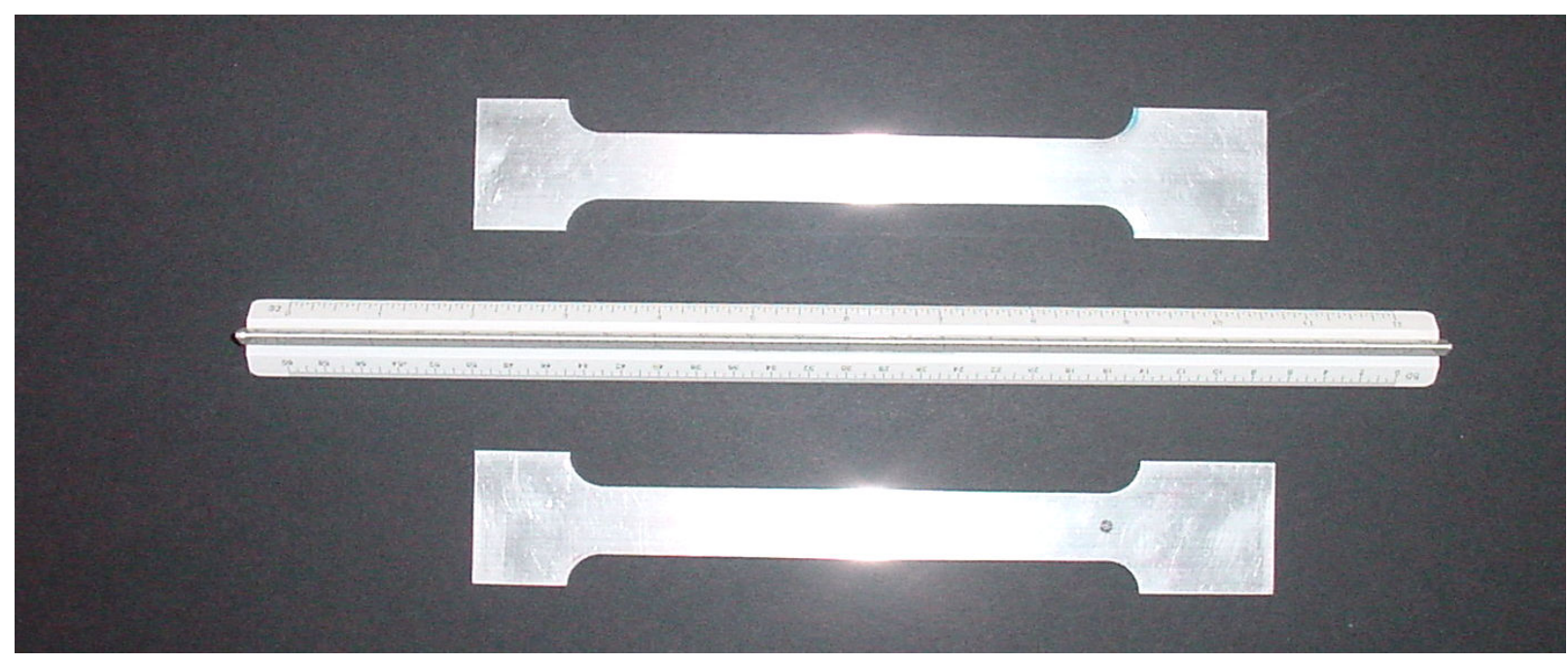

Figure 7 Two Specimens with Dog-Bone Geometries.

\section{IX - WHAT IS AVAILABLE TO THE INTERESTED PARTIES}

The following materials are available to those colleagues who may be interested in the reproduction of the apparatus and the use of this experiment:

1. Complete set of (most updated) blueprints of all home made components of the apparatus,

2. Comprehensive list of all commercial components and materials, their cost, and sources,

3. Most updated results and recommended procedures.

The above information may be obtained from the first author. A (preliminary) breakdown of the cost of the apparatus is shown in Appendix (C). A sample Laboratory Handout for the experiment is included in Appendix (D). 


\section{$\mathrm{X}$ - CONCLUSIONS}

The major objectives listed in section II have been achieved in this project. It is believed that in comparison with the commercially available counterparts of the proposed design and experiment, an alternative solution is offered to those colleagues who may be interested in adapting this proposed experiment and apparatus. This approach is beneficial for all parties involved; the researching/collaborating student(s), underclassmen who would benefit from such experiments and the enthusiastic instructors/laboratory coordinators who may be fighting with budgetary issues. The major remaining obstacle is the better understanding of why the experimental number of cycles are not falling within acceptable range of the predicted ones. So, further examination of the text book models/equations and search for ascertaining materials that do not suffer from a large standard deviation from the expected mean must continue.

\section{ACKNOWLEGMENTS}

The authors express special thanks to Alexander Michalchuk (department senior technician and machinist) for his continuous support and dedication to the project. They also thank the junior students (Andrew Maulbeck, Mary Anne Bitetto and Gregory Conway) for their valuable work and significant contributions. They certainly made a difference.

\section{REFERENCES}

1. Sepahpour, B., "Design of an Affordable Model Laboratory for Mechanical and Civil Engineering Programs", Proceedings of ASEE 2003 National Conference, Nashville, TN, June 2003.

2. Sepahpour, B., Clark, E. and Limberis, L. "Modular Lumped Mass Experiment", Proceedings of ASEE 2004 National Conference, Salt Lake City, Utah, June 2004.

3. Sepahpour, B., "Involving Undergraduate Students in Design of Experiments", Proceedings of ASEE 2002 National Conference, Montreal, Canada, June 2002.

4. Young, W. C. and Budynas G. Roark's Formulas for Stress and Strain, Seventh Edition. McGraw Hill, 2002.

5. Ugural, Ansel C. Mechanical Design: An Integrated Approach. International Edition. McGraw Hill Higher Education, 2004.

6. Juvinal, R. C., and Marshek, K. M. Fundamentals of Machine Component Design. Third Edition. John Wiley \& Sons, 2000.

7. Shigley, J. E. and Mischke, C. R. Standard Handbook of Machine Design. McGraw Hill, 1986.

8. Shigley, Joseph E. Mechanical Engineering Design, Third Edition, McGraw Hill, 1980.

\section{BIJAN SEPAHPOUR}

Bijan Sepahpour is a Professor of Mechanical Engineering at the College of New Jersey. He is actively involved in the generation of design-oriented exercises and development of laboratory apparatus and experiments in the areas of mechanics of materials and dynamics of machinery for undergraduate engineering programs. In the period of September 1997 to 2002, he served as the Primary and Technical advisor of TCNJ Lunar Rover team.

\section{SHOU-REI CHANG}

Shou-Rei Chang is an Assistant Professor of Mechanical Engineering at the College of New Jersey. Dr. Chang is an active member of SAE and has served as the Primary and Technical advisor of the Mini-Baja teams at the College of New Jersey for the past twelve years. For years, he served as the advisor for the department's ASME club. He teaches subjects related to Finite Elements, Machine Design and Advanced Stress Analyses. 


\section{Appendix A:}

\section{Approximate Stress Equations}

From Mechanics of Materials;

General Equation:

$$
\begin{aligned}
& \sigma_{\text {bending }}=\frac{M c}{I} \\
& \delta=-\frac{P L^{3}}{3 E I} \rightarrow \frac{-3 \delta E I}{L^{3}}=P \\
& M=P L=\frac{-3 \delta E I}{L^{3}} L=\frac{-3 \delta E I}{L^{2}} \\
& c=\frac{h}{2}, \quad I=\frac{1}{12} b h^{3} \\
& \sigma_{\text {bending }}=\frac{M c}{I}=\frac{\left(\frac{-3 \delta E I}{L^{2}}\right)\left(\frac{h}{2}\right)}{(I)}=\frac{-3 \delta E h}{2 L^{2}}
\end{aligned}
$$

It is interesting to note that this equation is independent of the width. For wide Beams a correction factor must be used. However, for the recommended sizes in this experiment, this is not necessary.

\section{Sample Data:}

Material: Aluminum 6061-T6 with certification.

The (average) Ultimate Strength, $\mathrm{S}_{\mathrm{U}}=47.34 \mathrm{kpsi}$,

The (average) Yield strength, $\mathrm{S}_{\mathrm{Y}}=44.16 \mathrm{kpsi}$,

Modulus of Elasticity, $\mathrm{E}=10,000 \mathrm{kpsi}$,

Thickness, $\mathrm{h}=0.25$ "

Width, $b=1.0$ "

Deflection, $\partial=1.0 "$

\begin{tabular}{|c|c|}
\hline $\begin{array}{c}\mathbf{L}_{\text {Effective }} \\
(\text { in) }\end{array}$ & $\begin{array}{c}\boldsymbol{\sigma}_{\text {Bending }} \\
(\mathbf{p s i})\end{array}$ \\
\hline 10.0 & 37,500 \\
\hline 9.75 & 39,400 \\
\hline 9.50 & 41,500 \\
\hline 9.375 & 42,700 \\
\hline 9.25 & 43,800 \\
\hline 9.125 & 45,000 \\
\hline 9.0 & 46,300 \\
\hline 8.875 & 47,600 \\
\hline
\end{tabular}




\section{Appendix A (Continued):}

\section{Equations for Number of Cycles to Failure}

For fully reversed bending, $\sigma_{m}=0$. So, Bending stress would be equal to Alternating stress as:

$$
\sigma_{\text {alternating }}=\frac{3 \delta E h}{2 L^{2}}
$$

The Number of cycles may be predicted (for steel specimen) by:

$$
N=\frac{10^{(b / m)}}{S_{e^{(1 / m)}}^{(b / m}}
$$

where

$$
\begin{aligned}
& m=\frac{1}{3} \log \left(\frac{0.9 S_{u t}}{S_{e}}\right) \\
& b=\log \left(\frac{\left(0.9 S_{u t}\right)^{2}}{S_{e}}\right)
\end{aligned}
$$

\section{Sample Data [8]:}

Material: Steel with:

Ultimate Strength, $\mathrm{S}_{\mathrm{U}}=385 \mathrm{Mpa}$,

Endurance Limit, $\mathrm{S}_{\mathrm{e}}=112 \mathrm{Mpa}$,

Required Life: $\mathrm{N}=70,000$ Cycles,

What Stress range/ fatigue strength $\left(\mathrm{S}_{\mathrm{f}}\right)$ is acceptable?

Calculated values for:

$m=0.163$

$b=3.029$

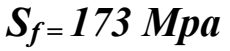


Appendix: B

\begin{tabular}{|c|c|c|c|c|c|c|c|}
\hline Specimen & $\begin{array}{c}\mathrm{D} \\
\mathrm{I} \\
\mathrm{M} .\end{array}$ & $\begin{array}{l}\text { Effective } \\
\text { Length }\end{array}$ & Deflection & $\begin{array}{c}\text { Cycles } \\
(\mathrm{N})\end{array}$ & Elapsed Time & Discontinuity & $\begin{array}{c}\text { Point of } \\
\text { Failure }\end{array}$ \\
\hline $\begin{array}{c}\text { Aluminum } \\
6063-\mathrm{T} 5\end{array}$ & $\begin{array}{c}1 / 8 ” \\
x \\
1 ”\end{array}$ & $5.5 "$ & \pm 0.4775 & $\begin{array}{l}79,150 \\
\end{array}$ & $\begin{array}{l}\approx 12.6 \text { hrs. } \\
\text { @ } 104.7 \text { RPM }\end{array}$ & None & $\begin{array}{l}@ \\
\text { Support }\end{array}$ \\
\hline $\begin{array}{c}\text { Aluminum } \\
6063-\mathrm{T} 5\end{array}$ & $\begin{array}{c}1 / 8 ” \\
x \\
1 ”\end{array}$ & $5.5 "$ & \pm 0.4775 & 108,450 & $\begin{array}{l}\approx 17.25 \text { hrs. } \\
\text { @ } 104.7 \text { RPM }\end{array}$ & None & $\begin{array}{l}\text { a } \\
\text { Support }\end{array}$ \\
\hline $\begin{array}{c}\text { Aluminum } \\
6063-\mathrm{T} 5\end{array}$ & $\begin{array}{c}1 / 8^{\prime \prime} \\
\mathrm{x} \\
1 ”\end{array}$ & $5.5^{\prime \prime}$ & \pm 0.4775 & 117,770 & $\begin{array}{l}\approx 18.7 \text { hrs. } \\
\text { @ 104.7 RPM }\end{array}$ & None & $\begin{array}{l}\text { a } \\
\text { Support }\end{array}$ \\
\hline $\begin{array}{l}\text { Aluminum } \\
6063-\mathrm{T} 5\end{array}$ & $\begin{array}{c}1 / 8 ” \\
x \\
1 ”\end{array}$ & $5.5^{\prime \prime}$ & \pm 0.4775 & 91,800 & $\begin{array}{l}\approx 14.61 \mathrm{hrs} . \\
\text { (a) } 104.7 \mathrm{RPM}\end{array}$ & $\begin{array}{l}\text { 1/8" Hole with } \\
\text { center 1" from } \\
\text { support }\end{array}$ & $\begin{array}{l}@ \\
\text { Hole }\end{array}$ \\
\hline $\begin{array}{l}\text { Aluminum } \\
6063-\mathrm{T} 5\end{array}$ & $\begin{array}{c}1 / 8 " \\
x \\
1 ” \\
\end{array}$ & $5.5 "$ & \pm 0.4775 & 108,890 & $\begin{array}{l}\approx 17.33 \text { hrs. } \\
\text { @104.7 RPM }\end{array}$ & $\begin{array}{l}\text { 1/8" Hole with } \\
\text { center 1" from } \\
\text { support }\end{array}$ & $\begin{array}{l}@ \\
\text { Hole }\end{array}$ \\
\hline $\begin{array}{c}\text { Aluminum } \\
6063-\mathrm{T} 5\end{array}$ & $\begin{array}{c}1 / 8 ” \\
x \\
1 ”\end{array}$ & $5.5 ”$ & \pm 0.4775 & 45,850 & $\begin{array}{l}\approx 7.3 \mathrm{hrs} . \\
\text { @ } 104.7 \mathrm{RPM}\end{array}$ & $\begin{array}{l}\text { 1/4" Hole with } \\
\text { center 1" from } \\
\text { support }\end{array}$ & $\begin{array}{l}@ \\
\text { Hole }\end{array}$ \\
\hline $\begin{array}{c}\text { Aluminum } \\
6063-\mathrm{T} 5\end{array}$ & $\begin{array}{c}1 / 16 \\
" x \\
1 "\end{array}$ & $4.6875 "$ & \pm 0.4775 & 134,500 & $\begin{array}{l}\approx 21.4 \mathrm{hrs} . \\
\text { @104.7 RPM }\end{array}$ & None & $\begin{array}{l}\text { a } \\
\text { Support }\end{array}$ \\
\hline $\begin{array}{c}\text { Aluminum } \\
5052-\mathrm{H} 32\end{array}$ & $\begin{array}{c}1 / 16 \\
" x \\
1 "\end{array}$ & $4.25 ”$ & \pm 0.5031 & 361,000 & $\begin{array}{l}\text { ₹65.15 hrs. } \\
@ 110 \mathrm{RPM}\end{array}$ & None & $\begin{array}{l}\text { @ } \\
\text { Support }\end{array}$ \\
\hline $\begin{array}{c}\text { Aluminum } \\
5052-\mathrm{H} 32\end{array}$ & $\begin{array}{c}1 / 16 \\
" x \\
1 "\end{array}$ & 4.25 & \pm 0.5031 & 417,150 & $\begin{array}{l}\approx 63.2 \text { hrs. } \\
@ 110 \text { RPM }\end{array}$ & None & $\begin{array}{l}\text { a } \\
\text { Support }\end{array}$ \\
\hline $\begin{array}{c}\text { Aluminum } \\
5052-\mathrm{H} 32\end{array}$ & $\begin{array}{c}1 / 16 \\
" x \\
1 "\end{array}$ & $4.25^{\prime \prime}$ & \pm 0.5031 & 648,000 & $\begin{array}{l}\approx 98.2 \text { hrs. } \\
\text { @110 RPM }\end{array}$ & None & $\begin{array}{l}\text { a } \\
\text { Support }\end{array}$ \\
\hline $\begin{array}{c}\text { Aluminum } \\
5052-\mathrm{H} 32\end{array}$ & $\begin{array}{c}1 / 16 \\
" \mathrm{x} \\
1 "\end{array}$ & $4.25 "$ & \pm 0.5031 & 265,850 & $\begin{array}{l}\approx 40.3 \text { hrs. } \\
\text { @110 RPM }\end{array}$ & $\begin{array}{l}\text { 1/4" Hole with } \\
\text { center } 1 \text { " from } \\
\text { support }\end{array}$ & $\begin{array}{l}\text { @ } \\
\text { Hole }\end{array}$ \\
\hline $\begin{array}{c}\text { Aluminum } \\
5052-\mathrm{H} 32\end{array}$ & $\begin{array}{c}1 / 16 \\
\text { "x } \\
1 "\end{array}$ & $4.25 ”$ & \pm 0.5031 & 782,190 & $\begin{array}{l}\approx 118.5 \mathrm{hrs} . \\
@ 110 \mathrm{RPM}\end{array}$ & $\begin{array}{l}\text { 1/8" Hole with } \\
\text { center } 1 \text { " from } \\
\text { support }\end{array}$ & $\begin{array}{l}\text { a } \\
\text { Hole }\end{array}$ \\
\hline $\begin{array}{c}\text { Aluminum } \\
6061-\mathrm{T} 65\end{array}$ & $\begin{array}{c}1 / 8 ” \\
x \\
1 ”\end{array}$ & "4.4375 & \pm 0.4775 & 1,975 & $\begin{array}{l}0.2 \mathrm{hrs} . \\
\text { @ } 104.7 \mathrm{RPM}\end{array}$ & None & $\begin{array}{l}\text { (a) } \\
\text { Support }\end{array}$ \\
\hline $\begin{array}{c}\text { Aluminum } \\
6061-T 65\end{array}$ & $\begin{array}{c}1 / 8^{\prime \prime} \\
\mathrm{x} \\
1 ”\end{array}$ & $4.625 "$ & \pm 0.5031 & 22,106 & $\begin{array}{l}\approx 1.6 \text { hrs. } \\
\text { a } 234 \text { RPM }\end{array}$ & None & $\begin{array}{l}\text { a } \\
\text { Support }\end{array}$ \\
\hline $\begin{array}{c}\text { Aluminum } \\
6061-T 65\end{array}$ & $\begin{array}{c}1 / 8 " \\
\mathrm{x} \\
1 ”\end{array}$ & $6.50 ”$ & \pm 0.5031 & 516,360 & $\begin{array}{l}\approx 71.7 \text { hrs. } \\
\text { @120 RPM }\end{array}$ & None & $\begin{array}{l}\text { a } \\
\text { Support }\end{array}$ \\
\hline $\begin{array}{c}1018 \mathrm{HR} \\
\text { Steel }\end{array}$ & $\begin{array}{c}1 / 8 " \\
x \\
1 ”\end{array}$ & $7.25 "$ & \pm 0.5031 & 44,360 & $\begin{array}{l}\approx 3.2 \text { hrs. } \\
\text { @234 RPM }\end{array}$ & None & $\begin{array}{l}\text { (a) } \\
\text { Support }\end{array}$ \\
\hline $\begin{array}{c}1018 \mathrm{HR} \\
\text { Steel }\end{array}$ & $\begin{array}{c}1 / 8 " \\
\mathrm{x} \\
1 ”\end{array}$ & $7.5^{\prime \prime}$ & \pm 0.5031 & 117,580 & $\begin{array}{l}\approx 8.4 \text { hrs. } \\
@ 234 \text { RPM }\end{array}$ & None & $\begin{array}{l}\text { a } \\
\text { Support }\end{array}$ \\
\hline $\begin{array}{c}1018 \mathrm{HR} \\
\text { Steel }\end{array}$ & $\begin{array}{c}1 / 8^{\prime \prime} \\
\mathrm{x} \\
1 ” \\
\end{array}$ & $8 "$ & \pm 0.5031 & 305,360 & $\begin{array}{l}\approx 21.75 \mathrm{hrs} . \\
@ 234 \mathrm{RPM}\end{array}$ & None & $\begin{array}{l}@ \\
\text { Support }\end{array}$ \\
\hline
\end{tabular}

Table B-1 Abridged Collected Data.

Proceedings of the 2005 American Society for Engineering Education Annual Conference \& Exposition Copyright $\mathbb{C}$ 2 2005, American Society for Engineering Education 


\section{Appendix: C}

\section{Parts List and Breakdown of the cost}

\begin{tabular}{|l|c|c|c|}
\hline \multicolumn{1}{|c|}{ Part } & Part No. & Quantity & Price (\$) \\
\hline \hline Steel Rod & & & \\
\hline Heim Joint & L0001 & 1 & 10.50 \\
\hline Nuts & L0002 & 2 & 7.50 \\
\hline Head Clamp & L0003 & 2 & - \\
\hline Screws (Head Clamp) & L0004 & 1 & $\sim 40.00$ \\
\hline Alternate Deflection Mechanism (Frame) & L0005 & 2 & - \\
\hline Alternate Deflection Mechanism (Beam) & L0006 & 1 & $\sim 40.00$ \\
\hline DC Gear-motor & L0007 & 1 & $\sim 40.00$ \\
\hline Disc & D0001 & 1 & 118.00 \\
\hline Motor Mount & D0002 & 1 & $\sim 30.00$ \\
\hline Motor Base plate & D0003 & 1 & $\sim 30.00$ \\
\hline Bolts (Motor Mount) & D0004 & 1 & $\sim 40.00$ \\
\hline Counter & D0005 & 4 & - \\
\hline Reed Switch & C0001 & 1 & 50.00 \\
\hline Counter Bracket & C0002 & 1 & 6.99 \\
\hline Relay & C0003 & 1 & $\sim 30.00$ \\
\hline PC Board & P0001 & 1 & 4.29 \\
\hline Micro Switch & P0002 & 1 & 1.79 \\
\hline Switch Pivoting Fork & P0003 & 2 & 2.69 \\
\hline Switch Mounting Plate & P0004 & 1 & $\sim 10$ \\
\hline & P0005 & 1 & $\sim 20$ \\
\hline & & & $525 /(1$ unit) \\
& & & $850 /(2$ units) \\
\hline
\end{tabular}

1. Overall Cost of the Materials and Components $\leq \$ 900$

2. Frame $\leq \$ 1050$

3. Beam supports $(2) \leq \$ 150$

3. Required Machining and Assembly Time:

I - Average Machining: About 18 hours (28 for two units)

II - Above Average Machining: About 5 hours ( 8 for two units)

III - Assembly of Frame and Components: About 6-8 hours 


\section{Appendix: D}

\section{Laboratory Handout \\ for \\ Low Cycle Finite Life Fatigue}

\section{Objectives:}

To gain familiarity with fully reversed bending fatigue.

To learn how to create and evaluate S-N diagrams.

To verify fatigue equations using test data.

\section{Equipment:}

Frame

Fatigue Tester Apparatus

\section{Materials:}

I - Three (3) steel / aluminum bars (for Low Cycle)

II - Three (3) steel / aluminum bars (for Finite Life)

III - Two (2) steel / aluminum bars (for examining the effects of Stress Concentration)

- One (1) having a $1 / 8$ inch diameter hole with its CENTER at $3 / 4$ " from the support,

- One (1) having a $1 / 4$ inch diameter hole with its CENTER at 3/4" from the support.

\section{Relevant Equations:}

$\sigma_{a}=\frac{3 \delta E h}{2 L^{2}}$

where $\sigma_{a}$ is the alternating stress, $\delta$ is deflection, $E$ is the modulus of elasticity, $h$ is the height of the beam, and $L$ is the effective length of the beam

$\frac{\sigma_{a}}{S_{e}}+\frac{\sigma_{m}}{S_{u}}=\frac{1}{n}$

and $\sigma_{a}$ is the alternating stress, $\sigma_{m}$ is the mean stress, $S_{e}$ is the endurance limit, $S_{u}$ is the ultimate strength, and $n$ is the factor of safety

$N=\frac{10^{(b / m)}}{S_{e}^{(1 / m)}}$, where $m=\frac{1}{3} \log \left(\frac{0.9 S_{u t}}{S_{e}}\right)$ and $b=\log \left(\frac{\left(0.9 S_{u t}\right)^{2}}{S_{e}}\right)$,

where $N$ is the approximate number of cycles to failure, $S_{e}$ is the endurance limit, and $S_{u t}$ is the ultimate strength

\section{Safety:}

Caution! Please be sure to wear safety goggles while examining the specimen during testing. The beam may behave violently upon failure. 


\section{Experiment Procedure:}

1. First, make sure the counter has been set to zero and the power to the motor is off.

2. Take the solid specimen, and install it in the fatigue tester. Use an effective length of 5.5 inches. Slide the support over to fit the beam. When the beam has been initially set up, tighten the screws on the clamp so that the beam fits snugly inside. Make sure that the beam is aligned in the center and perpendicular to the support before tightening the screws.

3. Calibrate the tester. Holding the support down (do not secure it to the frame yet), turn the disk so that the heim joint and rod are vertically in-line with the disk's central axis. The beam should be at its maximum deflection. Readjust the support to do this, if necessary. Holding the support in that position, turn the disk all the way around, ensuring that the rod will not hit either leg of the switching fork during normal operation. Once everything is in order, secure the support to the frame tightly.

4. Slide the front and rear plexi-glass protective covers over the apparatus.

5. The beam is now ready to be tested. Note the time before you start.

6. Put your safety goggles on BEFORE pressing the Power button.

7. While the beam is being tested, calculate the alternating stress and approximate number of cycles to failure for each of the specimens. Use a factor of safety of 1.1 against the Ultimate strength (for Low Cycle) and 1.1 against Yield strength for finite life). Create a table that includes these calculated values as well as columns for the experimental data. (The instructor might choose to include this step as part of a Pre-Lab Exercise instead.)

8. When the specimen fails, note the time and the number of cycles to failure.

9. Tabulate the results of the test(s) and calculate the percent Difference for the expected (theoretical) number of cycles.

10. Remove the specimen from the fatigue tester.

11. Repeat Steps 1 through 7 for each of the other specimens with the following adjustment. Change the factor of safety to 1.15, 1.2, 1.25, 1.3, etc. (Either for Low Cycle or Finite Life cases) and include the specimens with discontinuities (if desired).

12. Plot the result on an $\mathrm{S}-\mathrm{N}$ diagram. Compare the results to an existing $\mathrm{S}-\mathrm{N}$ diagram for the specified material.

\section{Discussion Questions}

- What are some of the causes for Fatigue Failure of materials?

- Comment on the statistical nature of fatigue failures.

- Define Endurance Strength and Endurance Limit and Compare them with each other.

- What can be done to minimize the possibility of Fatigue Failure and still conceive a product that is competitive in today's international markets? 